\title{
Synthesis of ternary bioactive glass derived aerogel and xerogel: study of their structure and bioactivity
}

\author{
Dalila Ksouri $^{1}$, Hafit Khireddine ${ }^{1}$, Ali Aksas ${ }^{1}$, Tiago Valente ${ }^{2}$, Fatima Bir ${ }^{1}$, Nadir Slimani ${ }^{2}$, \\ Belén Cabal ${ }^{3}$, Ramón Torrecillas ${ }^{3}$ and José Domingos Santos ${ }^{2}$ \\ ${ }^{1}$ Laboratoire de Génie de l'Environnement (LGE), Faculté de Technologie, Université de Bejaia, Bejaia, 06000, Algerie \\ ${ }^{2}$ Department of Materials, Faculty of Engineering, University of Porto (FEUP), Portugal \\ ${ }^{3}$ Nanomaterials and Nanotechnology Research Center (CINN), CSIC - University of Oviedo (UO), Avda de la Vega 4-6, \\ El Entrego 33940, San Martín del Rey Aurelio, Spain
}

\section{Article info}

Article history:

Received: $7^{\text {th }}$ June 2018

Accepted: $12^{\text {th }}$ November 2018

\section{Keywords:}

Aerogel

Bioactive glass

Bioactivity

Sol-gel

$63 \mathrm{~S}$

\begin{abstract}
In this work ternary bioactive glasses with the molar composition $63 \% \mathrm{SiO}_{2}, 28 \%$ $\mathrm{CaO}$, and $9 \% \mathrm{P}_{2} \mathrm{O}_{5}$ have been prepared via sol-gel processing route leading to xerogel or aerogel glasses, depending on the drying conditions. Two types of drying methods were used: atmospheric pressure drying (evaporative), to produce xerogels, and supercritical fluids drying, to obtain aerogels. Both dried gels were subjected to heat-treatment at three different temperatures: 400, 600 and $800{ }^{\circ} \mathrm{C}$ in order to the removal of synthesis byproducts and structural modifications. The resulting materials were characterized by X-ray diffraction (XRD), Fourier transforms infrared spectroscopy (FTIR), scanning electron microscopy (SEM), thermal gravimetric analysis (TGA) and differential thermal analysis (DTA), and by in vitro bioactivity tests in simulated body fluid. The influence of the drying and the sintering temperature of their structure, morphology, and bioactivity of the final products were evaluated. The results show a good bioactivity of xerogel and aerogel bioactive glass powders with the formation of an apatite layer after one day of immersion in SBF solution for aerogel bioactive glass powders and a particle size less than $10 \mathrm{~nm}$. An apatite layer formed after 3 days in the case of xerogel bioactive glass powders and a particle size around $100 \mathrm{~nm}$.
\end{abstract}

(c) University of SS. Cyril and Methodius in Trnava

\section{Introduction}

The bioactive glasses constitute an important group of biomaterials that have wide application in medical and dental fields (Mehdipour et al. 2012; Al-Noaman et al. 2012). In fact, when bioactive glasses are in contact with body fluid or tissue, they generate a series of physical and chemical reactions leading to the formation of hydroxyapatite surface layer (Zhitomirsky et al. 2009; Bellucci et al. 2011). Certain compositions of bioactive glasses containing $\mathrm{SiO}_{2}-\mathrm{CaO}-\mathrm{P}_{2} \mathrm{O}_{5}$ can bond to both soft and hard tissue without any intervening fibrous layer.

The method of elaboration of the bioactive glasses is greatly influencing the results of the bioactivity and biocompatibility. Sol-gel technique is the most widely used for the synthesis of bioactive glasses (Li et al. 2013). The sol-gel process involves hydrolysis, polymerization, gelation, drying, and a dehydration process. Gels are usually classified as aerogels and xerogels. When the liquid from the gel is evaporated at room temperature, the solid gels left behind are called xerogels. Whereas, when 
the liquid from the gel is extracted at the supercritical state of liquid, these materials are called aerogels. The removal of solvent above its critical point occurs with no capillary pressure because there are no liquid-vapor interfaces. Thus in the aerogel process, there is a greatly reduced driving force for shrinkage (Catauro et al. 2015). The conditions of drying the gel and sintering temperature in the sol-gel method are also an important factor affecting the structure, morphology, and bioactivity of the bioactive glasses. The bioactivity responses depend upon the physical and chemical characteristics of the materials and particularly upon its chemical composition, crystallinity, particle size, surface structure, microstructure and surface roughness (Deligianni et al. 2001; Valerio et al. 2004). There has been increased interest in fabricating sol-gel derived nanoscale bioactive glasses. Nanoscale particulate bioactive glasses have shown advantages over conventional (micrometer-sized) bioactive glasses due to their large surface area and enhanced solubility as well as reactivity coupled with the possibility to induce nanotopographic surface features in composite materials (ErolTaygun 2013).

In this work, ternary bioactive glasses with the molar composition $63 \% \mathrm{SiO}_{2}, 28 \% \mathrm{CaO}$, and $9 \% \mathrm{P}_{2} \mathrm{O}_{5}$, known as $63 \mathrm{~S}$ bioactive glass, have been prepared via sol-gel processing route leading to xerogel or aerogel glasses, depending on the drying conditions. In the literature, there are many articles about $63 \mathrm{~S}$ obtained by atmospheric pressure drying (Catauro et al. 2015), but none by supercritical drying, at least for the author's knowledge. This paper compares the structure, morphology and in vitro bioactivity of identical chemical composition bioactive glasses produced by the sol-gel process at the supercritical condition of ethanol (aerogel) and by the most used synthesis route to obtain bioactive glasses (xerogel). The influence of the calcination temperatures was also evaluated.

\section{Experimental}

\section{Preparation of bioactive glass powders}

The composition of studied bioactive glass belongs to the ternary system $\mathrm{SiO}_{2}-\mathrm{CaO}-\mathrm{P}_{2} \mathrm{O}_{5}$ with $63 \mathrm{~S}$ composition: $63 \mathrm{SiO}_{2} 28 \mathrm{CaO} 9 \mathrm{P}_{2} \mathrm{O}_{5}$ (mol \%). Glass powders were synthesized through a sol-gel process. Xerogel bioactive glasses (labelled as XG) were prepared in a similar way as previously described by other authors (Doostmohamadi et al. 2011). Briefly, tetraethylorthosilicate (TEOS), which was selected as a silica precursor for the sol, was added to ethanol as an alcoholic media and the mixture was stirred for $30 \mathrm{~min}$. Distilled water was added to the solution and allowed to mix until the solution became clear with $\mathrm{H}_{2} \mathrm{O}$ : TEOS molar ratio of $4: 1$. After $30 \mathrm{~min}$, triethyl phosphate (TEP) was added to the stirring solution and after another 20 min, calcium nitrate tetrahydrate was added to the mixture. Hydrochloric acid $(\mathrm{HCl}, 2 \mathrm{~N})$ was used as a catalyst and the final solution was stirred for one hour additional. To obtain a xerogel bioactive glass powder $(\mathrm{XG})$, the solution was heated at $60{ }^{\circ} \mathrm{C}$ for $10 \mathrm{~h}$ and dried at $130{ }^{\circ} \mathrm{C}$ for $20 \mathrm{~h}$. Another identical solution was autoclaved at supercritical conditions of ethanol solvent (pressure of 63 bars, a temperature of $243{ }^{\circ} \mathrm{C}$ ) to obtain an aerogel bioactive glass (labelled as AG).

The dried gel powders (xerogel and aerogel) were crushed and calcined at different temperatures: 400, 600 and $800{ }^{\circ} \mathrm{C}$, for $2 \mathrm{~h}$ with a heating rate of $5{ }^{\circ} \mathrm{C} / \mathrm{min}$, then the furnace was naturally cooled down. The obtained glasses were labelled as XG 400 and AG 400 when the calcination takes place at $400{ }^{\circ} \mathrm{C}$, XG 600 and $\mathrm{AG} 600$ when it was at $600{ }^{\circ} \mathrm{C}, \mathrm{XG} 800$ and $\mathrm{AG} 800$ at $800{ }^{\circ} \mathrm{C}$.

\section{Characterization of bioactive glasses}

Thermal behaviour of these bioactive glasses was performed with a thermogravimetric-differential thermal analyzer (TA Instruments, Q600) in a flowing air atmosphere at a heating rate of $5{ }^{\circ} \mathrm{C} / \mathrm{min}$ from the ambient temperature to $1,000{ }^{\circ} \mathrm{C}$. X-ray diffraction (XRD) analysis of the bioactive glasses was conducted on a Bruker D8 Discover diffractometer using $\mathrm{CuK} \alpha$ radiation $(\lambda=1,54060 \AA)$ working at $40 \mathrm{kV}$ and $40 \mathrm{~mA}$ in a step-scanning mode from $10^{\circ}$ to $80^{\circ}$, at a scan speed of $0.04 \%$. The morphology of the obtained bioactive glasses was studied by scanning electron microscopy (SEM) Nova Nano SEM 200 equipped with the Silicon SUTW-Sapphire EDAX detector, 

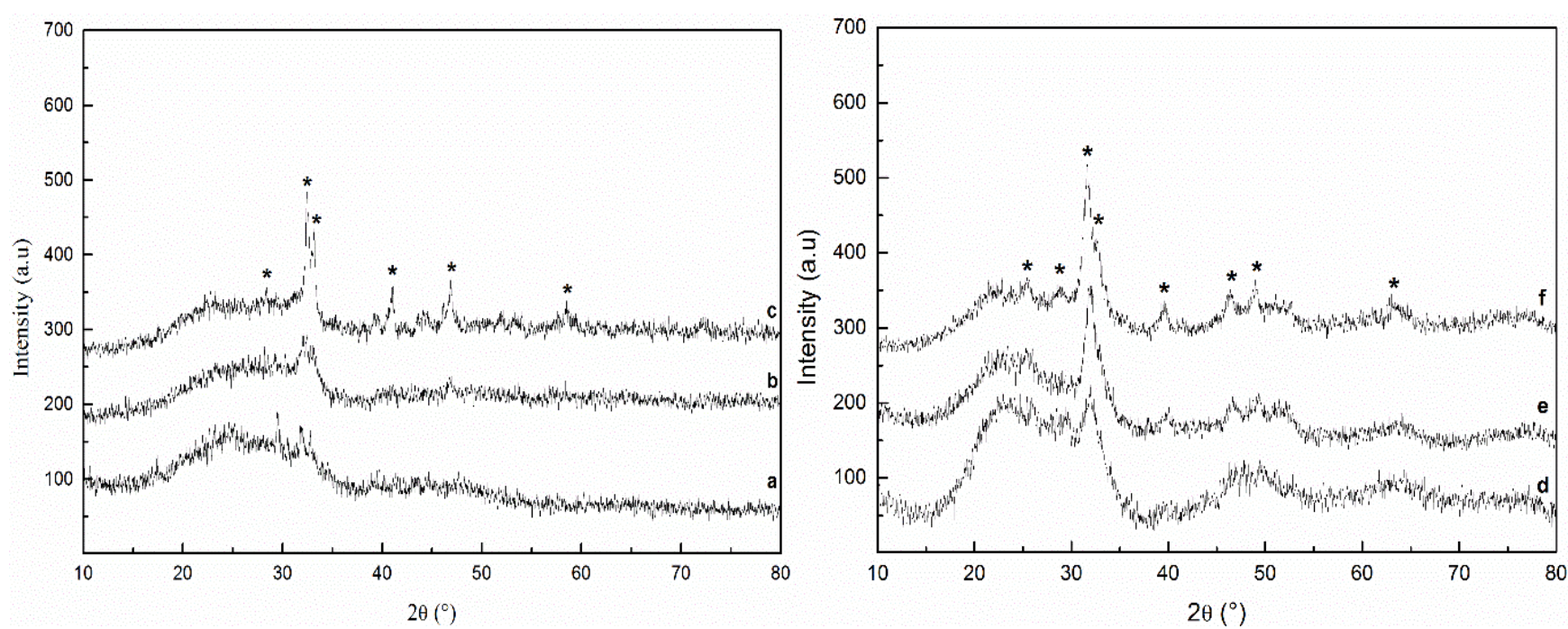

Fig. 1. XRD pattern of bioactive glass powders: a- XG 400, b- XG 600, c- XG 800, d- AG 400, e- AG 600 and f- AG 800 .

resolution: 125.01. The microstructure of the surface of the samples in vitro tests was performed using a High resolution (Schottky) Environmental Scanning Electron Microscope with X-Ray Microanalysis and Electron Backscattered Diffraction analysis: Quanta 400 FEG ESEM / EDAX Genesis X4M. Samples were coated with $\mathrm{Au} / \mathrm{Pd}$ thin film, by sputtering, using the SPI Module Sputter Coater equipment. Glasses were also characterized using transmission electron microscopy (TEM) (JEOL-2000EX).

\section{In vitro bioactivity}

The evaluation of in vitro bioactivity of the bioactive glass powders prepared by xerogel and aerogel at different calcined temperature was performed using SBF solution prepared according to Kokubo protocol (Kokubo 1990). In vitro bioactivity tests were used to evaluate the formation of an apatite layer on the surface of the bioactive glass pellets, considered as an indicator of in vivo bioactivity (Leonor et al. 2002). To study the bioactivity, the bioactive glass powders were pressed into pellets of $15 \mathrm{~mm}$ in diameter and $2 \mathrm{~mm}$ in thickness and were soaked in simulated body fluid (SBF) solution prepared according to the protocol developed by Kokubo (1990) at $37^{\circ} \mathrm{C}$ and $\mathrm{pH}=7.4$ for 1,3 and 7 days with a surface area to volume ratio of $0.1 \mathrm{~cm}^{-1}$ (Zhao et al. 2005). The SBF solution of soaking samples was refreshed every two days. After being soaked, the pellets were extracted from the solution rinsed with deionized water then dried in air at room temperature. The pellets without soaking in SBF are labelled as zero-day $\left(\begin{array}{ll}0 & \mathrm{~d}\end{array}\right)$. The formation of an apatite layer on the surface of the pellets was investigated by X-Ray diffraction (XRD) for phase analysis, scanning electron microscopy (SEM) for morphology and energy dispersive spectroscopy (EDS) for elemental analysis.

\section{Results and Discussion}

\section{Characterization of the bioactive glass powders}

Bioactive glass powders were characterized by different analysis methods in order to evaluate the drying treatment and the influence of calcination temperature on the structure, morphology, and bioactivity of bioactive glass powders.

The phase formation behaviour of the bioactive glass powders derived from xerogel and aerogel at different calcination temperatures was investigated by XRD and the results patterns are shown in Fig. 1. The powders calcined at $400{ }^{\circ} \mathrm{C}$ and $600{ }^{\circ} \mathrm{C}$ for both xerogel and aerogel bioactive glass powders take an amorphous state indicating an intern disorder and glassy nature of these powders (Saboori et al. 2009; Radev et al. 2012). The heat treatment at $600{ }^{\circ} \mathrm{C}$ resulted in some crystallite growth. While, the powders calcined at $800{ }^{\circ} \mathrm{C}$ illustrated a crystalline structure referred to the wollastonite $\left(\mathrm{CaSiO}_{3}\right)$ (Rainer et al. 2008), 

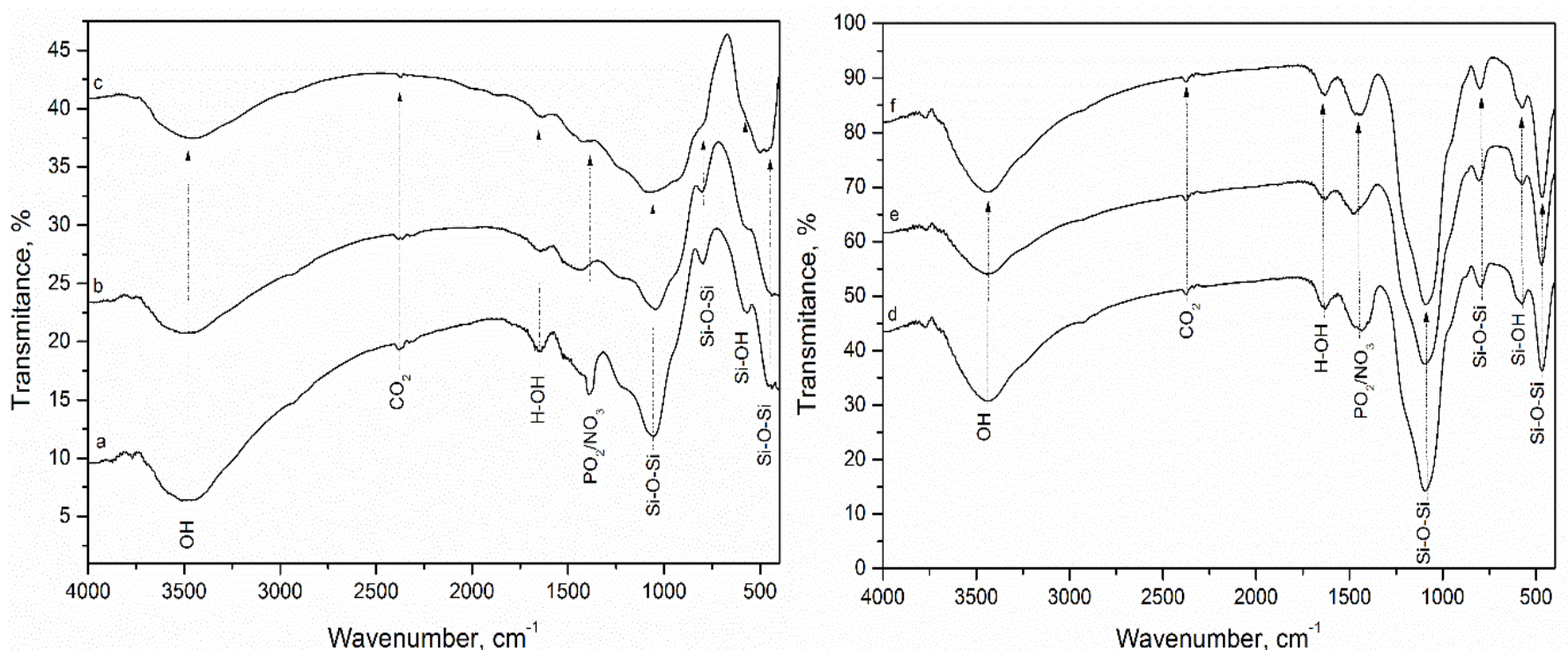

Fig. 2. FTIR spectra of bioactive glass powders: a- XG 400, b- XG 600, c- XG 800, d- AG 400, e- AG 600 and f- AG 800.

this specified that the crystallization process depending on the heat treatment conditions (Elbatal et al. 2003).

The formation of bioactive glass powders was further confirmed by FTIR spectral analysis illustrated in Fig. 2. All the samples showed an adsorption band at $1,036-1,082 \mathrm{~cm}^{-1}$ assigned to the $\mathrm{Si}-\mathrm{O}-\mathrm{Si}$ asymmetric bond stretching vibrations, the bond in the $785-790 \mathrm{~cm}^{-1}$ region is attributed to the symmetric $\mathrm{Si}-\mathrm{O}-\mathrm{Si}$ stretching vibrations (Lucas-Girot et al. 2011; Jiang et al. 2011) and the absorption around $453-463 \mathrm{~cm}^{-1}$ is due to the vibrational mode of the bending of $\mathrm{Si}-\mathrm{O}-\mathrm{Si}$ ( $\mathrm{Ma}$ et al. 2011) indicating that all the samples are essentially composed of Si-O-Si network. These bands are narrower in the case of aerogel bioactive glass, and become larger with the increase of calcination temperature especially for xerogel
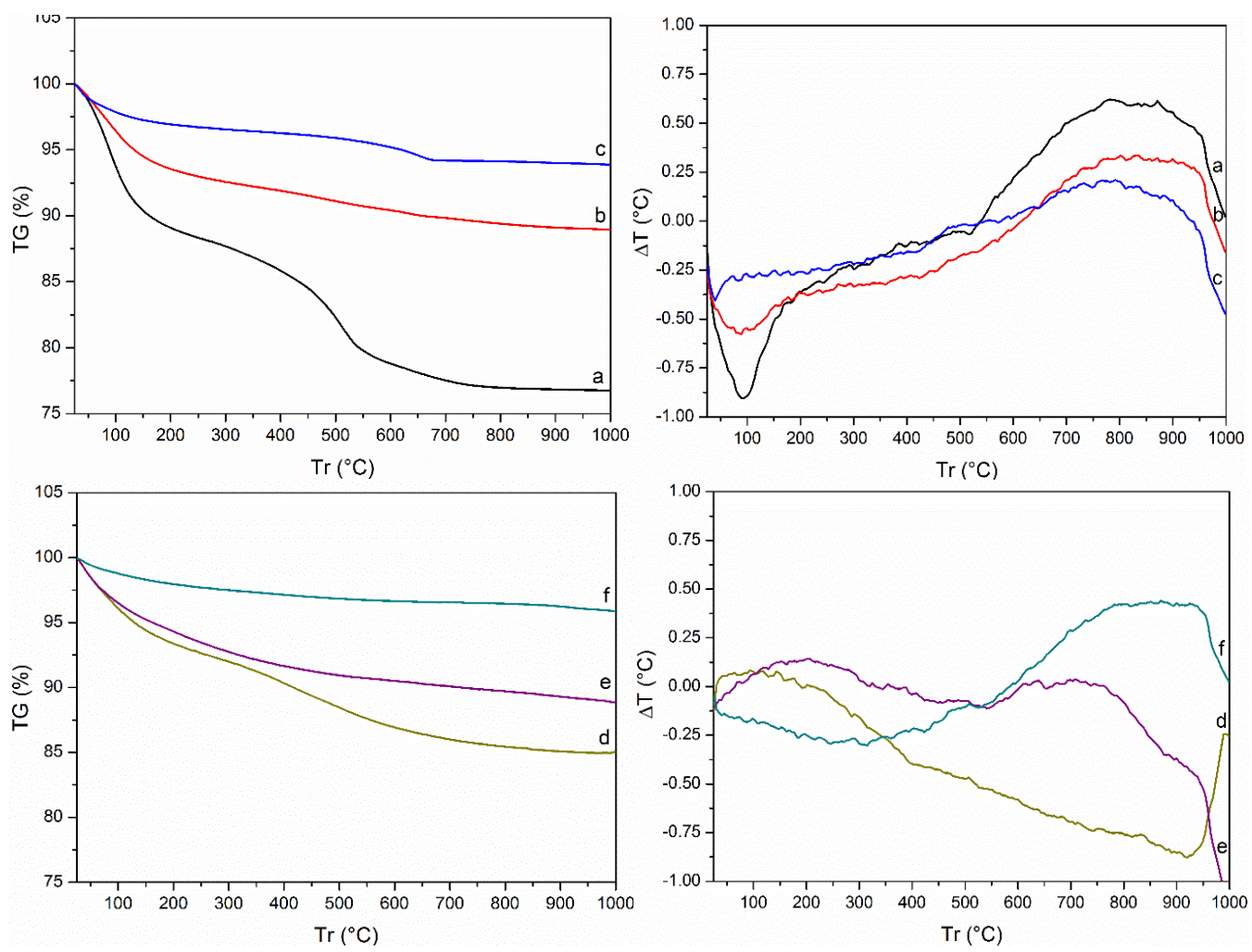

Fig. 3. TG/ DTA curves of prepared bioactive glass powders: $\mathrm{a}-\mathrm{XG}$ $400, \quad b-\quad X G \quad 600$, c- XG 800, d- AG 400, e- AG 600 and f- AG 800 . 

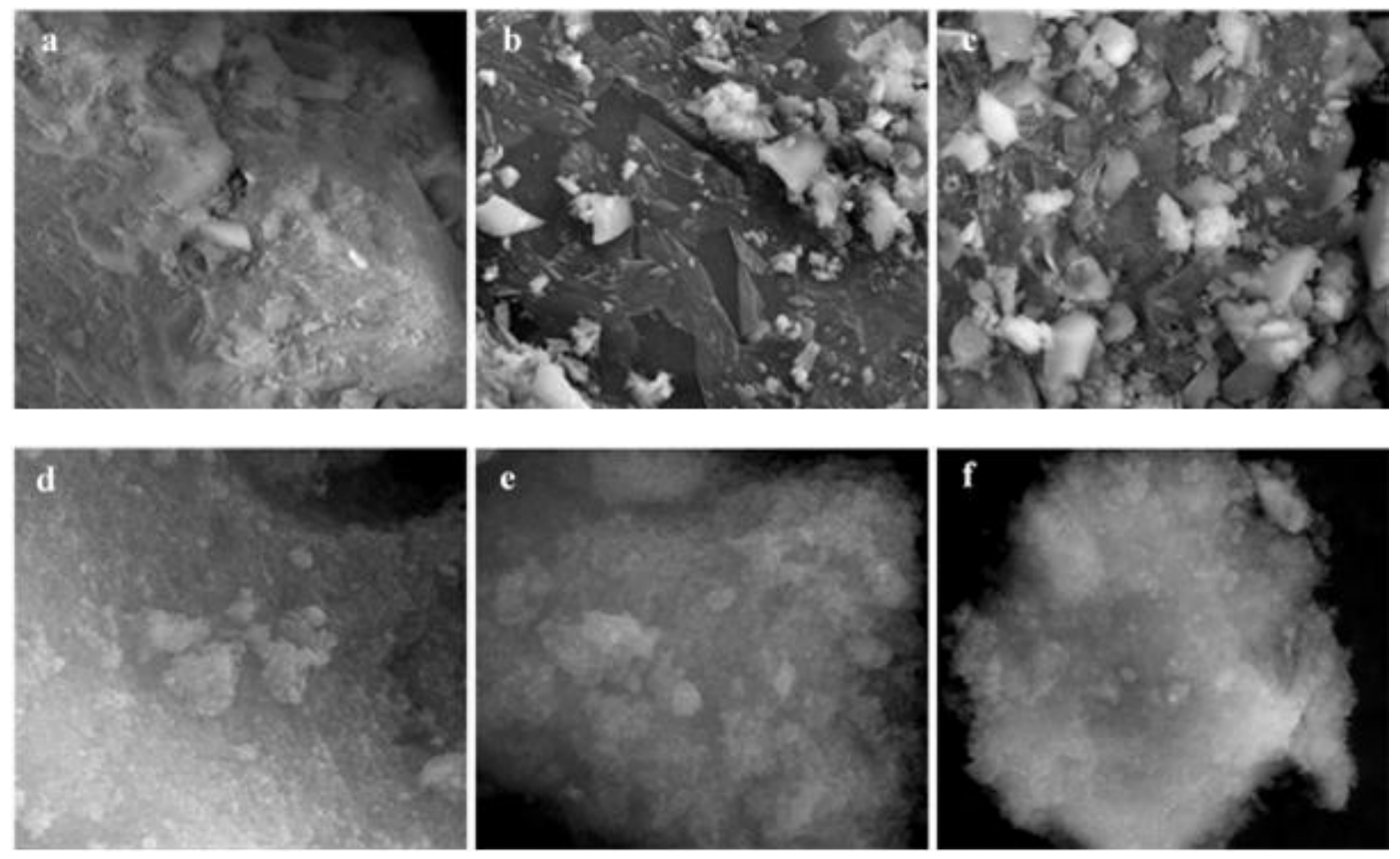

Fig. 4. SEM micrographs of bioactive glass powders: a- XG 400, b- XG 600, c- XG 800, d- AG 400, e- AG 600 and $\mathrm{f}-\mathrm{AG} 800$.

bioactive glass.

FTIR spectra involve the band around $956 \mathrm{~cm}^{-1}$ attributed to the stretching vibrations of $\mathrm{Si}-\mathrm{OH}$ bonds (Tarasyuk et al. 2006), the band at $1,396 \mathrm{~cm}^{-1}$ is assigned to the vibrations of $\mathrm{PO}_{2}$ and/or $\mathrm{NO}_{3}$ groups (Qian et al. 2009), this band disappear in xerogel bioactive glass powders calcined at $600{ }^{\circ} \mathrm{C}$ and $800{ }^{\circ} \mathrm{C}$ but remains in the aerogel bioactive glass powders which can be explained by the transformation of $\mathrm{PO}_{2}$ to the oxide $\mathrm{P}_{2} \mathrm{O}_{5}$ and/or the degradation of the nitrate $\mathrm{NO}_{3}$ after calcination up to $600{ }^{\circ} \mathrm{C}$ in the case of the xerogel bioactive powder However, the remaining of the band at $1,396 \mathrm{~cm}^{-1}$ in the aerogel bioactive glass powders can be explained by their porous structure that contains small pores with a nanometric scale, which may imprison the $\mathrm{PO}_{2}$ and/or $\mathrm{NO}_{3}$ that are not reacted during the sol-gel process. The band at $2,372 \mathrm{~cm}^{-1}$ is attributed to the adsorption of $\mathrm{CO}_{2}$ by the atmospheric (Hajiali et al. 2010). The weak inflection at $1,620-1,653 \mathrm{~cm}^{-1}$ and the broad band centred at $3,438-3,455 \mathrm{~cm}^{-1}$ are assigned to $\mathrm{O}-\mathrm{H}$ band of adsorbed water and structural hydroxyl group respectively (Mehdipour and Afshar 2012). The samples were characterized by thermo-gravimetric and differential thermal analysis (TG/DTA). The Fig. 3 a-f shows TG/DTA traces of the developed bioactive glass powders. The results indicated that the weight loss decreases with increasing calcination temperature. Overall,

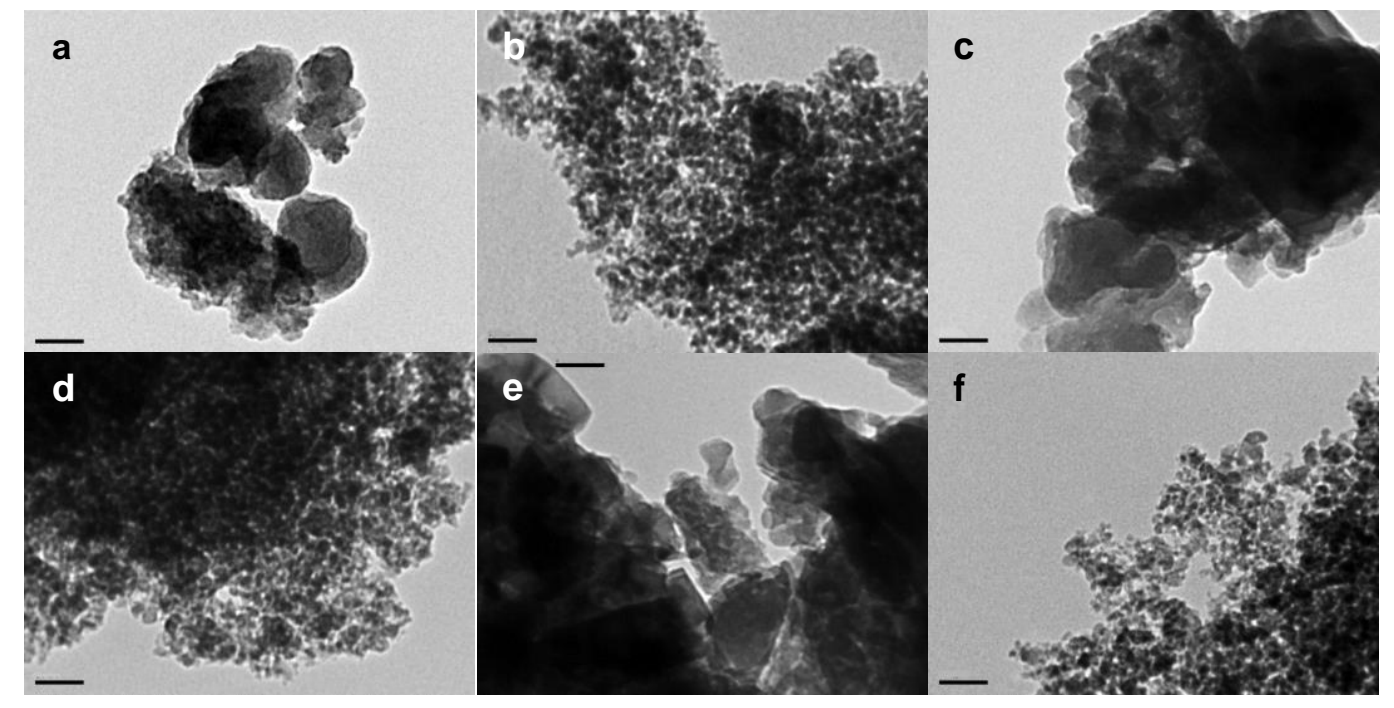

Fig. 5. TEM micrographs of prepared bioactive glass powders: $a-$ XG 400, b- XG 600, c- XG 800, d- AG 400, e- AG 600 and f-AG 800 . 

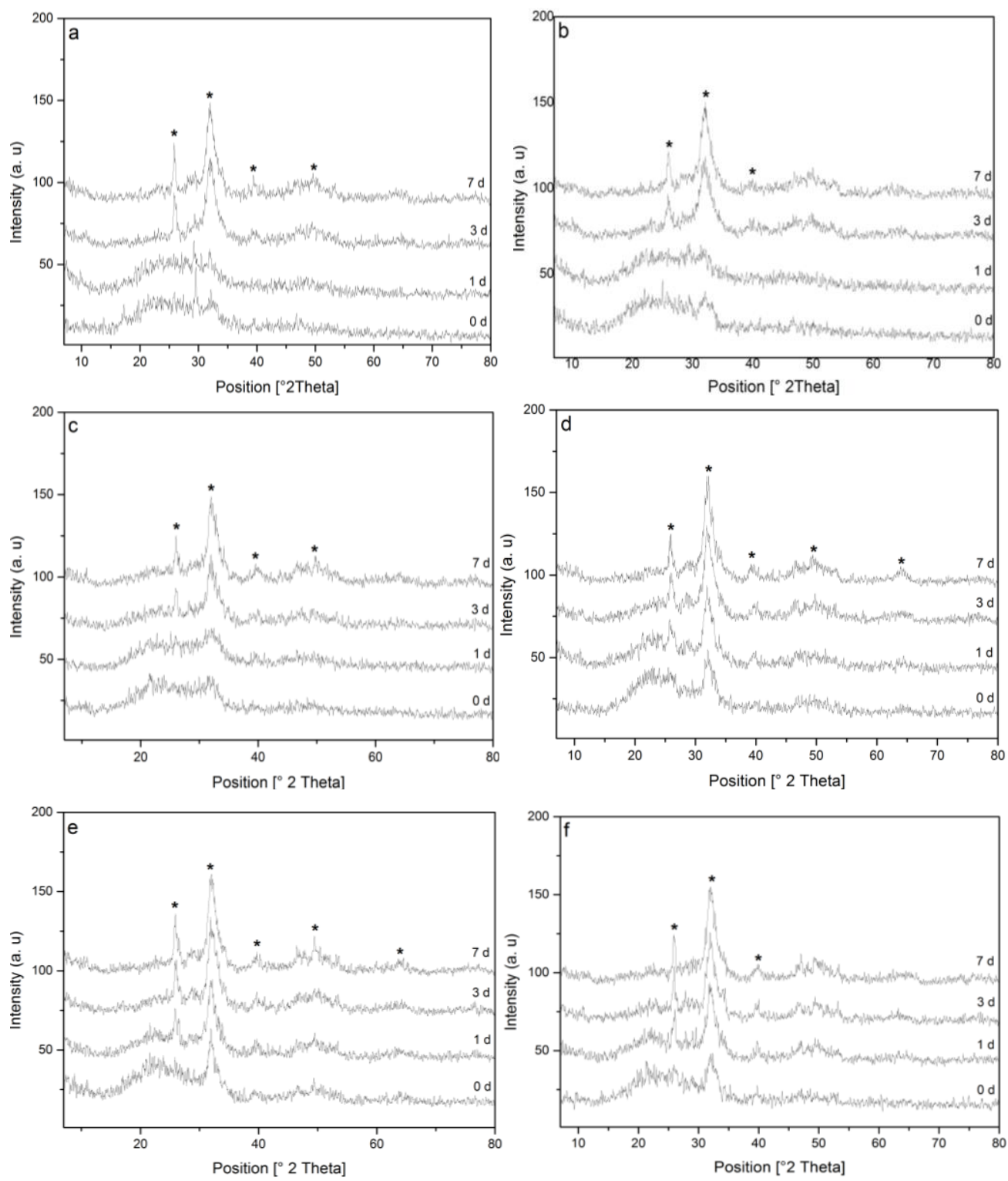

Fig. 6. XRD pattern of bioglasses before and after soaking in SBF solution for 1, 3 and 7 days:

a- XG 400, b- XG 600, c- XG 800, d- AG 400, e- AG 600 and f- AG 800.

xerogel bioactive glass powder calcined at $400{ }^{\circ} \mathrm{C}$ exhibits a greater weight loss with $23 \%$ following by aerogel bioactive glass powder calcined at $400{ }^{\circ} \mathrm{C}$ with $15 \%$. The xerogel and aerogel bioactive glass powders calcined at $600{ }^{\circ} \mathrm{C}$ shows the same weight loss with $11 \%$. Whereas, the xerogel bioactive glass powder calcined at $800{ }^{\circ} \mathrm{C}$ shows a slight difference comparing to aerogel bioactive glass powder calcined at $800{ }^{\circ} \mathrm{C}$ with $6 \%$ and $4 \%$, respectively.

The first mass loss stage occurs around $100{ }^{\circ} \mathrm{C}$ to $150{ }^{\circ} \mathrm{C}$ can be associated with the endothermic evaporation of the adsorbed water on the surface of the bioactive glass powders. A second weight loss occurs at $350{ }^{\circ} \mathrm{C}$ to $420{ }^{\circ} \mathrm{C}$ is due to the elimination of the remaining organic groups and the residual nitrates used during the sol-gel process (Riti et al. 2015). In addition, a third weight loss in the range of $550{ }^{\circ} \mathrm{C}$ to $660{ }^{\circ} \mathrm{C}$ is probably attributed to the polycondensation of residuals alkoxides (Cestari 2016), these loss weights can be explained by the glass transition temperature of bioactive glass particles (Gönen et al. 2016). A fourth weight loss at $690{ }^{\circ} \mathrm{C}$ and $850{ }^{\circ} \mathrm{C}$ is observed in the case of xerogel and aerogel bioactive glass powders calcined at $800{ }^{\circ} \mathrm{C}$ respectively can be attributed also to the structural transformation (Charoensuk et al. 2013). The different temperature of the fourth weight loss for the xerogel and aerogel bioactive glass powders could be attributed to their different particle size after the processes. The exothermic final process 

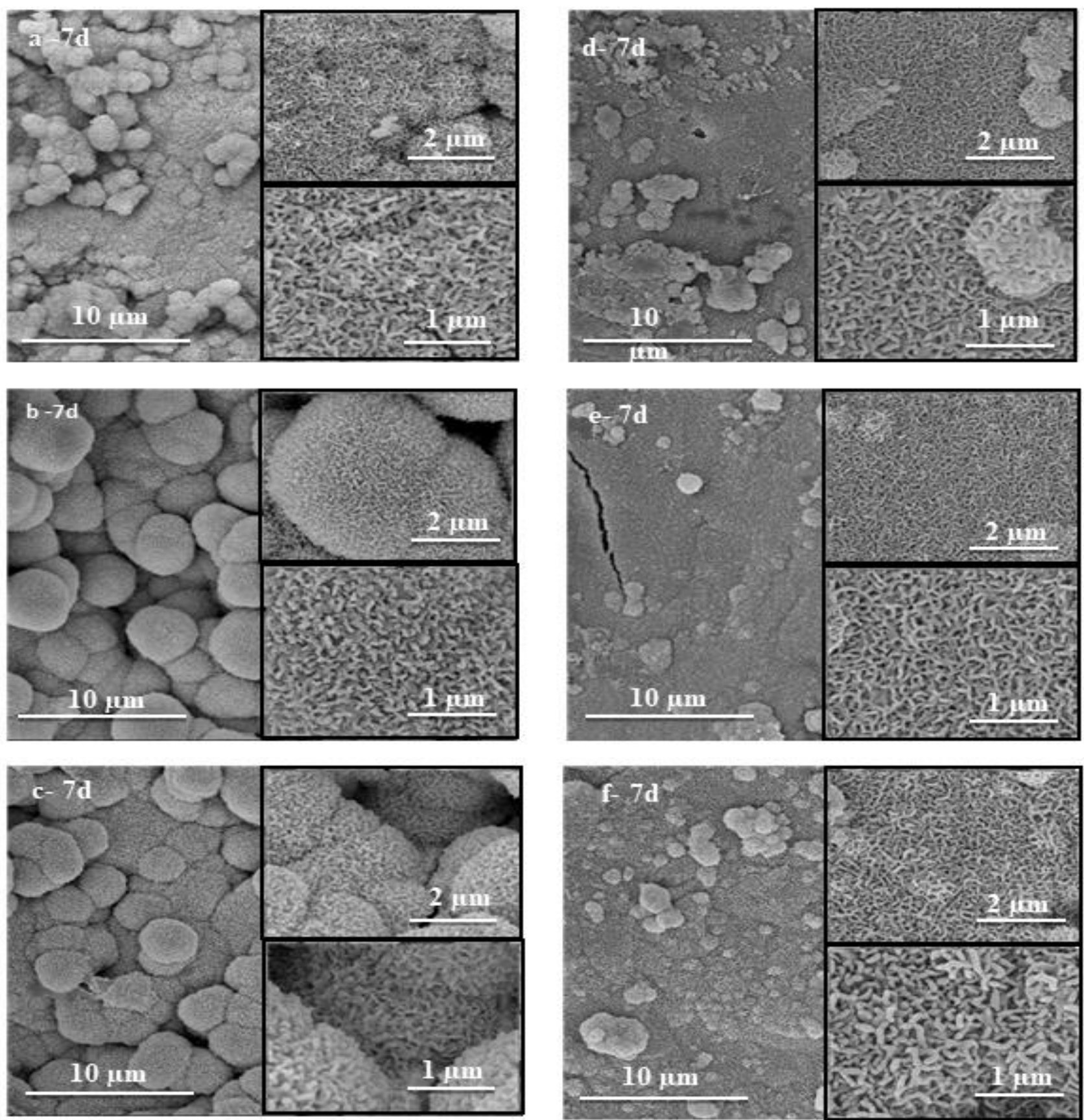

Fig. 7. SEM morphologies of bioactive glass pellets after soaking in SBF solution for 7 days: a- XG 400, b- XG 600, c- XG 800, d- AG 400, e- AG 600 and f- AG 800.

occurs at approximately $850^{\circ} \mathrm{C}$ and is related to the onset of crystallization. Thermal processing drives off the $-\mathrm{OH}$ groups, causing further formation of $\mathrm{O}-\mathrm{Si}-\mathrm{O}$ bonds. The nitrates were also removed during stabilization by thermal processing.

The drying conditions have an important effect on the porosity. SEM micrographs (Fig. 4) show that the obtained aerogel bioactive glass powders are less dense and more porous in comparison to xerogel bioactive glass powders. Aerogels are mostly constituted of agglomerate spherical particles with a spongy structure. Whereas xerogel bioactive glass powders are constituted of blocks, the apparition of white particles on the surface can be assigned to a crystal phase.

The values of particle size obtained from the results of image analysis of TEM micrographs also confirmed the SEM results. Xerogel bioactive glass powders are composed of uniform particles readily identified by TEM (Fig. 5 a-c).

The micrographs show a size particle between $20 \mathrm{~nm}$ to $100 \mathrm{~nm}$ with inhomogeneity of forms and 
shapes. On the contrary, the aerogel network can be described as an assembly of clusters. These are formed by the aggregation of small homogeneous spherical particles with a size less than $10 \mathrm{~nm}$. The TEM micrographs revealed that size of the bioactive glass powders increases with increasing of calcination temperature. This is can be explained by the structural contraction and densification during the sol-gel process of the developed bioactive glass powders and weight loss because of the polycondensation of the residual alkoxide (Cestari 2016).

\section{In vitro assays}

The Fig. 6 shows the XRD patterns of bioactive glass pellets prepared from xerogel and aerogel before and after soaking in SBF solution for 1, 3 and 7 days. It can be seen (Fig. 6), the apparition of two diffraction peaks at 26 and $32^{\circ}(2 \theta)$ corresponding to (002) and (211) reflections of an apatite phase (Nayak et al. 2010; Ma et al. 2011). These peaks are observed after one day in the case of aerogel bioactive glass pellets (Fig. $6 \mathrm{~d}-\mathrm{f}$ ) and after 3 days for xerogel bioactive glass pellets (Fig. 6 a-c). These results indicate that an apatite crystal was deposited on the surface of the pallets. However, the diffraction peaks are less defined in xerogel bioactive glass pellets that may be due to a lower thickness of the calcium phosphate layer. The Elemental analysis of bioactive glass pellets before and after soaking in SBF for 1, 3 and 7 days was confirmed by energy dispersive $\mathrm{X}$-ray analysis (EDS) technique. The results (Table 1) showed a remarkable increase in the intensity of calcium and phosphorus elements and reduction of the silica in all the pellets from the first day of immersion in SBF solution. The decrease of silica in xerogel and aerogel bioactive glass pellets calcined at $400{ }^{\circ} \mathrm{C}$ and $800{ }^{\circ} \mathrm{C}$ after 1 day of immersion showed a slight difference compared to bioactive glass pellets without immersion 0 day. After 7 days of immersion, we noticed the almost total disappearance of element $\mathrm{Si}$ and the appearance only of elements $\mathrm{Ca}$ and $\mathrm{P}$ which improve that the surfaces of the pallets are covered by an apatite layer. Excellent bioactive and resorbent properties of xerogel $63 \mathrm{~S}$ bioactive glasses have been previously reported.
Table 1. The quantitative EDS analysis spectrum of bioglasses before and after soaking in SBF solution for 1, 3 and 7 days.

\begin{tabular}{lrrrrr}
\hline Samples /At & \multicolumn{1}{l}{ C } & \multicolumn{1}{l}{ O } & \multicolumn{1}{c}{ Si } & \multicolumn{1}{c}{ P } & \multicolumn{1}{c}{ Ca } \\
\hline [\% $]$ & 5.74 & 61.01 & 21.04 & 2.68 & 9.52 \\
XG 400 & 5.05 & 60.91 & 14.04 & 7.23 & 12.76 \\
XG 400, 1d & 7.43 & 57.26 & 0.47 & 12.07 & 22.76 \\
XG 400, 7d & 6.10 & 55.87 & 0.46 & 13.11 & 24.43 \\
XG 600 & 8.67 & 58.59 & 20.20 & 2.61 & 9.93 \\
XG 600, 1d & 5.90 & 61.71 & 6.65 & 10.00 & 15.74 \\
XG 600, 3d & 5.53 & 57.71 & 0.89 & 12.17 & 23.70 \\
XG 600,7d & 5.76 & 58.64 & 0.57 & 12.66 & 22.36 \\
XG 800 & 5.41 & 58.12 & 23.52 & 2.94 & 10.02 \\
XG 800, 1d & 15.62 & 50.50 & 12.20 & 7.76 & 13.93 \\
XG 800, 3d & 14.61 & 50.55 & 4.66 & 10.68 & 19.51 \\
XG 800,7d & 11.92 & 53.03 & 2.18 & 12.39 & 20.48 \\
AG 400 & 3.99 & 60.98 & 23.76 & 4.11 & 7.16 \\
AG 400, 1d & 5.62 & 59.00 & 17.64 & 6.80 & 10.94 \\
AG 400, 3d & 9.18 & 57.08 & 4.72 & 11.21 & 17.82 \\
AG 400,7d & 8.11 & 58.25 & 1.53 & 12.45 & 19.66 \\
AG 600 & 4.23 & 59.48 & 24.96 & 4.08 & 7.24 \\
AG 600, 1d & 12.91 & 52.63 & 7.57 & 10.69 & 16.20 \\
AG 600, 3d & 10.99 & 55.39 & 1.74 & 13.02 & 18.88 \\
AG 600,7d & 16.09 & 51.83 & 1.10 & 12.61 & 18.37 \\
AG 800 & 5.09 & 59.66 & 24.10 & 3.16 & 8.00 \\
AG 800, 1d & 5.36 & 57.43 & 14.57 & 8.75 & 13.89 \\
AG 800, 3d & 5.99 & 56.99 & 6.91 & 11.63 & 18.49 \\
AG 800,7d & 6.00 & 56.74 & 2.84 & 12.70 & 21.72 \\
\hline
\end{tabular}

The formation of bone-like apatite layer during bioactivity experiments was also evaluated by examining the change of surface morphology during the incubation in SBF solution. The Fig. 7 showed the surface morphology of samples before and after soaking in SBF for 1, 3 and 7 days. The results showed that the surface morphology changed with incubation periods. After 1 day soaking in SBF compared to 0 days as control, the micrographs revealed the formation of individual spherical apatite grain in the case of xerogel bioactive glass pellets and a fully covered surface with an extensive calcium phosphate precipitate with tiny flak on the shape for aerogel bioactive glass pellets. With increasing incubation periods, the formation of apatite grains increase too, after 3 days soaking the surface of xerogel bioactive glass pellets was fully covered by an apatite layer, and this layer was composed of numerous spherical particles. On the other hand, the more growing of the apatite layer for aerogel bioactive glass pellets. However, the density of the precipitate (apatite layer) increased significantly after 7 days of immersion. The ability of aerogel bioactive glass to promote rapid formation of apatite layer after only one day of soaking can be explained by faster 
interchange between $\mathrm{Ca}^{2+}$ ions of aerogel bioactive glass and the $\mathrm{H}_{3} \mathrm{O}^{+}$from $\mathrm{SBF}$ that can give rise to the formation of $\mathrm{Si}-\mathrm{OH}$ groups on the surface of the pellets that induces the apatite nucleation (Petil et al. 2011). In addition, the rate of apatite formation depends on differences in the texture and morphology of xerogel and aerogel bioactive glass that improve the apatite deposition in SBF is extensive in rougher regions and sparse in flatter regions (Pereira et al. 1995; Petil et al. 2011). The formation of an apatite layer on the surface of the pellets is also more important when the temperature is increased. It found that the aerogel bioactive glass powder has a nanoparticle size and the formation of an apatite layer on the surface is faster and it is designated to compensate an organ or tissue deficient in a pathology, trauma or aging tissues (El-Kady et al. 2010; Hajiali et al. 2010).

\section{Conclusions}

In this study, ternary bioactive glass powders were successfully synthesized via the sol-gel route from two types of dried gel: xerogel and aerogel. The results obtained show that the texture of elaborated bioactive glass powders is strongly influenced by the drying conditions of the gels and the calcination temperature. It found that the aerogel bioactive glass powders are characterized by less dense and spongy structure with a particles size less than $10 \mathrm{~nm}$ and an apatite layer is obtained after only one day of immersion in SBF solution. However, the xerogel bioactive glass powders presented a dense structure with a particle size around $100 \mathrm{~nm}$ and a surface covered with an apatite layer after three days of immersion in SBF solution. The bioactive glass powders calcined at $800{ }^{\circ} \mathrm{C}$ presented a good properties and in vivo tests will be interesting for this powder in order to improve its viability to be used in regenerative medicine: filling bone defects, prosthetic coatings in orthopedic surgery, maxillofacial and dental.

\section{References}

Al-Noaman A, Rawlinson SCF, Hill RG (2012) The role of $\mathrm{MgO}$ on thermal properties, structure and bioactivity of bioactive glass coating for dental implants. J. NonCryst. Solids 358: 3019-3027.
Bellucci D, Cannillo V, Sola A (2011) Calcium and potassium addition to facilitate the sintering of bioactive glasses. Mater. Lett. 65: 1825-1827.

Catauro M, Bollino F, Renella RA, Papale F (2015) Sol gel synthesis of glasses: influence of the heat treatment on their bioactivity and biocompatibility. Ceram. Int. 41: 12578-12588.

Cestari A (2016) Sol-gel methods for synthesis of aluminosilicates for dental applications. J. Dentistry 55: 105-113.

Charoensuk T, Sirisathitkul Ch, Boonyang U (2013) Thermal analysis of mesoporous and macroporous bioactive glasses synthezed by Sol-Gel method. Rev. Rom. Mater. 43: 320-325

Deligianni DD, Katsala ND, Koutsoukos PG, Missirlis YF (2001) Effect of surface roughness of hydroxyapatite on human bone marrow cell adhesion, proliferation, differentiation and detachment strength. Biomaterials 22: 87-96.

Doostmohamadi A, Monshi A, Fathi MH, Karbasi S, Braissant O, Daniels QU (2011) Direct cytotoxicity evaluation of $63 \mathrm{~S}$ bioactive glass and bone-derived hydroxyapatite particles using yeast model and human chondrocyte cells by microcalorimetry. J. Mater. Sci. Mater. Med. 22: 2293-2300.

ElBatal HA, Azooz MA, Khalil EMA, Soltan Monem A, Hamdy YM (2003) Characterization of some bioglassceramics. Mater. Chem. Phys. 80: 599-609.

El-Kady AM, Saad EA, El-Hady ABM, Farag MM (2010) Synthesis of silicate glass/poly (L-lactide) composite scaffolds by freeze-extraction technique: Characterization and in vitro bioactivity evaluation. Ceram. Int. 36: 995-1009.

Erol-Taygun M, Zheng K, Boccaccini AR (2013) Nanoscale Bioactive Glasses in Medical Applications. Int. J. Appl. Glass Sci. 4: 136-148.

Gönen SÖ, Erol TM, Aktürk A, Küçükbayrak S (2016) Fabrication of nanocomposite mat through incorporating bioactive glass particles into gelatin/poly $(\varepsilon-$ caprolactone) nanofibers by using Box-Behnken design. Mater. Sci. Eng. C 67: 684-693.

Hajiali H, Karbasi S, Hosseinalipour M, Rezaie HR (2010) Preparation of a novel biodegradable nanocomposite scaffold based on poly (3-hydroxybutyrate)/bioglass nanoparticles for bone tissue engineering. J. Mater. Sci. Mater Med. 21: 2125-2132.

Jiang P, Lin H, Xing R, Jiang J, Qu F (2011) Synthesis of multifunctional macroporous-mesoporous $\mathrm{TiO}_{2-}$ bioglasses for bone tissue engineering. J. Sol-Gel Sci. Technol. 61: 421-428.

Kokubo T (1990) Surface chemistry of bioactive glassceramics. J. Non-Cryst. Solids 120: 138-151.

Leonor IB, Sousa RA, Cunha AM, Reis RL (2002) Novel starch thermoplastic/Bioglass composites: Mechanical properties, degradation behavior and in-vitro bioactivity. J. Metr. Sci. Mater. Med. 13: 939-945.

Li HC, Wang DG, Hu JH, Che CZ (2013) Effect of various additives on microstructure, mechanical properties, and in vitro bioactivity of sodium oxide-calcium oxidesilica-phosphorus pentoxide glass-ceramics. J. Colloid 
Interface Sci. 405: 296-304.

Lucas-Girot A, Mezahi FZ, Mami M, Oudadesse H (2011) Abdelhamid Harabi. Marie Le Floch. Sol-gel synthesis of a new composition of bioactive glass in the quaternary system $\mathrm{SiO}_{2}-\mathrm{CaO}-\mathrm{Na}_{2} \mathrm{O}-\mathrm{P}_{2} \mathrm{O}_{5}$ Comparison with melting method. J. Non-Cryst. Solids 357: 3322-3327.

Ma J, Chen CZ, Wang DG, Hu JH (2011) Synthesis, characterization and in vitro bioactivity of magnesiumdoped sol-gel glass and glass-ceramics. Ceram. Int. 37: 1637-1644.

Mehdipour M, Afshar A (2012) A study of the electrophoretic deposition of bioactive glass-chitosan composite coating. Ceram. Int. 38: 471-476.

Nayak JP, Kumar S, Bera J (2010) Sol-gel synthesis of bioglass-ceramics using rice husk ash as a source for silica and its characterization. J. Non-Cryst. Solids 356: 1447-1451.

Pereira MM, Clark AE, Hench LL (1995) Effect of texture on the rate of hydroxyapatite formation on gel-silica surface. J. Am. Ceram. Soc. 78: 463-468.

Petil O, Zanotto ED, Hench LL (2011) Highly bioactive $\mathrm{P}_{2} \mathrm{O}_{5}-\mathrm{Na}_{2} \mathrm{O}-\mathrm{CaO}-\mathrm{SiO}_{2}$ glass-ceramics. J. Non-Cryst. Solids. 292: 115-126.

Qian J, Kang Y, Wei Z, Zhang W (2009) Fabrication and characterization of biomorphic 45S5 bioglass scaffold from sugarcane. Mater. Sci. Eng. C 29: 1361-1364.

Radev L, Hristova K, Jordanov V, Fernandes MHV, Salvado IMM (2012) In vitro bioactivity of $70 \mathrm{Wt} . \%$ $\mathrm{SiO}_{2}-30 \mathrm{Wt} \% \mathrm{CaO}$ sol-gel glass, doped with 1,3 and 5 Wt.\% NbF5. Centr. Eur. J. Chem. 10: 137-145.
Rainer A, Giannitelli SM, Abbruzzese F, Traversa F, Licoccia S, Trombetta M (2008) Fabrication of bioactive glassceramic foams mimicking human bone portions for regenerative medicine. Acta Biomater. 4: 362-369.

Riti PI, Vulpoi A, Simon V (2015) Effect of $\mathrm{pH}$ dependent gelation time and calcination temperature on silica network in $\mathrm{SiO}_{2}-\mathrm{CaO}$ and $\mathrm{SiO}_{2}-\mathrm{MgO}$ glasses. J. NonCryst. Solids. 411: 76-84.

Saboori A, Rabiee M, Moztarzadeh F, Sheikhi M, Tahriri M, Karimi M (2009) Synthesis, characterization and in vitro bioactivity of sol-gel-derived $\mathrm{SiO}_{2}-\mathrm{CaO}-\mathrm{P}_{2} \mathrm{O}_{5}-\mathrm{MgO}$ bioglass. Mater. Sci. Eng. C 29: 335-340.

Tarasyuk E, Shilova OA, Bochkin AM, Pomogailo AD (2006) Investigation into the influence of organic modifiers and ultradispersed hybrid fillers on the structure and properties of glass-ceramic coating prepared by the sol-gel method. Glass Phys. Chem. 32: 439-447.

Valerio P, Pereira MM, Goes AM, Leite MF (2004) The effect of ionic products from bioactive glass dissolution on osteoblast proliferation and collagen production. Biomaterials 25: 2941-2948.

Zhao W, Wang J, Zhai W, Wang Z, Chang J (2005) The selfsetting properties and in vitro bioactivity of tricalcium silicate. Biomaterials 26: 6113-6121.

Zhitomirsky D, Roether JA, Boccaccini AR, Zhitomirsky I (2009) Electrophorotic deposition of bioactive glass/polymer composite coating with and without HA nanoparticle inclusions for biomedical applications. J. Mater. Process. Technol. 209: 1853-1860. 